Open

\title{
Endogenous IL-21 regulates pathogenic mucosal CD4 T-cell responses during enhanced RSV disease in mice
}

\author{
JS Dodd ${ }^{1}$, D Clark ${ }^{1,2}, \mathrm{R}_{\text {Muir }}{ }^{1}, \mathrm{C}$ Korpis $^{1}{ }^{\text {and PJM Openshaw }}{ }^{1}$
}

A role for interleukin-21 (IL-21) has recently been found in several diseases, but contribution to mucosal defences has not been described. In BALB/c mice infected with respiratory syncytial virus (RSV), IL-21 depletion had little effect in primary infection. However, depletion of mice during priming with recombinant vaccinia expressing RSV G protein (which primes RSV-specific T helper type 2 cells and causes lung eosinophilia during RSV infection) further exacerbated pathology during RSV challenge, with reduced viral clearance and impaired virus-specific serum antibody responses. This enhancement was accompanied by lymphocyte, neutrophil, and antigen-presenting cell recruitment to the lungs, with increased bronchoalveolar lavage interferon- $\gamma$ and IL-17 levels. Adoptive transfer of splenic CD4 Tcells from depleted mice into naive recipients replicated these effects, indicating that IL-21 mediates its effects via CD4 T cells. Endogenous IL-21, therefore, has potent and specific effects on mucosal antiviral responses, assisting viral clearance, regulating pulmonary $\mathrm{T}$ - and $\mathrm{B}$-cell responses, and inhibiting $\mathrm{IL}-17$ production.

\section{INTRODUCTION}

Respiratory syncytial virus (RSV) is a major cause of viral bronchiolitis in infants, ${ }^{1}$ also causing seasonal exacerbations and deaths due to respiratory disease in elderly persons. ${ }^{2}$ The immune response to RSV infection is complex, involving innate, humoral, and cellular immune responses; all have a role in both antiviral protection and disease pathogenesis. ${ }^{3}$ RSV vaccine development has been hampered by the failure of a formalin-inactivated RSV vaccine in the 1960s, which led to disease exacerbation after subsequent natural viral infection associated with excessive lung inflammation. Several hypotheses have been advanced to explain disease exacerbation, including vaccine-triggered $\mathrm{T}$ helper type 2 (Th2)-biased CD4 $\mathrm{T}$-cell responses caused by carbonylation ${ }^{4}$ and low-avidity poorly neutralizing antibodies that form immune complexes in the lungs. ${ }^{5}$ In addition, IL-17 production by CD4 T cells has recently been implicated in enhanced disease.,

Interleukin (IL)-21 is a regulatory cytokine produced by activated $\mathrm{CD} 4 \mathrm{~T}$ cells ${ }^{8}$ natural killer (NK) T cells, ${ }^{9} \mathrm{~T}$ follicular helper cells ${ }^{10}$ and Th17 cells. ${ }^{11}$ Although IL-21 production is restricted to a few cell types, its receptor (IL-21R), is expressed on CD4 and CD8 T cells, B cells, NK cells, NK T cells, $\gamma \delta$ T cells, dendritic cells (DCs), macrophages, keratinocytes, and fibroblasts. ${ }^{12,13} \mathrm{IL}-21$ has been reported to control the differentiation and functional activity of T cells, ${ }^{8} \mathrm{~B}$ cells,${ }^{14}$ and NK cells, ${ }^{15}$ to limit the differentiation of regulatory $\mathrm{T}$ cells, ${ }^{16}$ and promote $\mathrm{T}$ cells resistance to regulatory-T-cell-mediated immune suppression. ${ }^{17}$ It also stimulates epithelial cells and fibroblasts to produce inflammatory mediators. ${ }^{13,18}$

Our understanding of the role of IL-21 in T-cell differentiation is evolving rapidly. The differentiation of naive $\mathrm{T}$ cells into Th2 cells may be enhanced by IL- $21,{ }^{19}$ while under other conditions it may drive $\mathrm{T}$ cells and NK cells towards interferon (IFN)- $\gamma$ production ${ }^{20}$ and promote Th17 differentiation. ${ }^{21,22}$ IL-21, like IL-10, is produced by all pro-inflammatory T-cell lineages, indicating that it may have crucial anti-inflammatory functions by regulating T-cell activation. For example, IL-21 has been shown to inhibit immediate hypersensitivity reactions

${ }^{1}$ Section of Respiratory Infection, Faculty of Medicine, Centre for Respiratory Infections, National Heart and Lung Institute, Imperial College, London, UK. Correspondence: PJM Openshaw (p.openshaw@imperial.ac.uk)

2Present address: LSHTM, Keppel Street, London WC1E 7HT, UK (D.C.); Centre for Infection and Immunity, School of Medicine, Dentistry and Biomedical Sciences, Queens University, Belfast, UK (R.M.).

Received 3 February 2012; accepted 10 October 2012; published online 21 November 2012. doi:10.1038/mi.2012.108 
in the skin, ${ }^{23}$ and CD8 T-cell responses to tumors. ${ }^{24}$ It boosts IL10 production in visceral leishmaniasis ${ }^{25}$ by human naive $\mathrm{CD} 4 \mathrm{~T}$ cells, ${ }^{26} \operatorname{Tr} 1$ cells, ${ }^{27}$ and NK cells. ${ }^{28}$ A lack of IL-21 may lead to dysregulated responses against hepatitis B virus in the young ${ }^{29}$ and boost IL-17 production by CD4 T cells in Listeria monocytogenes infection. ${ }^{30}$ Increased IL-21 expression by CD4 T cells was associated with control of HIV replication, but this may simply reflect greater T-cell activity. ${ }^{31,32}$ Its increased production has also been positively correlated in several diseases, but this again may reflect self-regulation by activated $\mathrm{T}$ cells. ${ }^{33,34}$

Although the role of IL-21 has been studied in many diseases, there is little known about its role in respiratory infections. In this study, we have used a well-characterized mouse model of immunization-enhanced RSV bronchiolitis to investigate the role of IL-21 on CD4 T-cell responses to RSV infection. We found that IL-21 depletion at immunization compromised viral clearance, significantly inhibited production of virus-specific serum antibody levels, and caused pronounced dysregulation of the CD4 T-cell response.

\section{RESULTS}

IL-21 depletion increases CD4 T-cell responses to primary RSV challenge

We determined the effect of IL-21 depletion on responses to primary RSV infection in naive mice. Disease (measured by weight loss) is negligible until $\mathrm{d} 5-7$ post challenge (PC) and peaks at d6-7 PC. Although weight loss increased with IL-21 depletion, the change was not significant (Figure 1a). In primary infection, RSV replication is detectable at $\mathrm{d} 2 \mathrm{PC}$, peaks at $\mathrm{d} 4 \mathrm{PC}$, and returns to baseline by $\mathrm{d} 7 \mathrm{PC}$. IL-21 depletion did not alter this kinetic, but there was a significant decrease in $\mathrm{L}$ gene expression levels in depleted mice on d4 PC (Figure 1b).

Next, we measured T-cell and NK cell recruitment into the airways. CD8 T-cell and NK cell recruitment or activation were unaffected by depletion, but there was a significant increase in CD4 T-cell recruitment at d7 PC (Figure 1c), especially of ICOS (inducible costimulatory molecule)-expressing CD4 cells (Figure 1d). We then tested the effect of IL-21 depletion on bronchoalveolar lavage (BAL) cytokines and chemokines, markers of immune activation in the lung. We could not detect IL-21 (data not shown), and IL-4 and tumor necrosis factor levels were not affected by IL-21 depletion. By contrast, the proinflammatory mediators IFN- $\gamma$ and RANTES (regulated and normal $\mathrm{T}$ cell expressed and secreted) both increased in depleted mice (Figure 1e). We observed a threefold increase in the proportion of $\mathrm{CD} 4 \mathrm{~T}$ cells producing IFN- $\gamma$ in IL-21depleted mice (Figure 1f). Thus, endogenous IL-21 tends to restrain inflammation and antiviral defense, but the effects are mild in primary RSV infection and are mediated primarily via CD4 T cells.

\section{IL-21 depletion during priming exacerbates immunopathology after RSV challenge}

In order to enhance the dependency of inflammation on the CD4 T-cell response and to explore the effects of IL-21 in more detail, we opted to study the effects of IL-21 on RSV disease augmented by previous senitization via cutaneous immunization with recombinant vaccinia virus expressing RSV surface glycoprotein $\mathrm{G}(\mathrm{rVV}-\mathrm{G})$. This prime-challenge regimen induces a strong CD4 T-cell-mediated, Th2-driven immunopathology that causes lung eosinophilia after RSV challenge ${ }^{35}$ and parallels some of the clinical and immunological features observed in infantile RSV bronchiolitis. Depletion had no effect on vaccinia lesions or on resolution of cutaneous infection (data not depicted), and our analysis, therefore, focussed on the effects of IL-21 depletion on the pulmonary response to RSV challenge.

rVV-G sensitized mice lost weight immediately after RSV challenge, peaking at $\sim 15 \%$ on $\mathrm{d} 4 \mathrm{PC}$, with recovery by $\mathrm{d} 7 \mathrm{PC}$ (Figure 2a). IL-21 depletion significantly increased the magnitude of weight loss, peaking at $\sim 25 \%$ on d5-6 PC. Moreover, the kinetic of recovery was delayed with no mouse recovering fully by $\mathrm{d} 8 \mathrm{PC}$. In some experiments, weight loss was followed to d14 PC but still showed incomplete recovery (data not depicted).

Weight loss correlates with recruitment of activated cells to the lung and airway; therefore, we studied cell recruitment by flow cytometry, observing that both total BAL and lung cell counts were significantly increased in IL-21-depleted mice on d5 PC. Specifically, we observed significant increases in recruitment of CD4 T cells, CD8 T cells, and NK cells to the BAL (Figure 2c). Activity of recruited T cells (as measured by ICOS and CD69 expression) was also greater in depleted mice (data not shown). By contrast, we observed a significant reduction in B cells in IL-21-depleted mice (Figure 2c). IL-21 depletion also boosted granulocytosis: we observed a significant increase in neutrophil $\left(\mathrm{CD}^{-} / \mathrm{B}^{-} 20^{-} / \mathrm{CD} 1 \mathrm{~b}^{+} / \mathrm{CCR} 3^{-}\right)$ recruitment but not eosinophilia $\left(\mathrm{CD} 3^{-} / \mathrm{B}_{2} 20^{-} / \mathrm{CD}^{-} \mathrm{bb}^{+} /\right.$ $\mathrm{CCR}^{+}$; Figure 2d). Recruitment of DCs was also observed to increase in depleted mice using three separate markers: MHCII (major histocompatibility complex II), CD11b, and CD11c (Figure 2e). Similar changes were also observed in recruitment to the lung tissue (data not shown). We also measured IFN- $\gamma$, IL-4, IL-10, and IL-17 levels in the BAL fluid of mice on d5 PC and found that there were significant increases in IFN- $\gamma$, IL-10, and IL-17, and a significant decrease in IL-4, in IL-21-depleted mice (Figure 2f). IL-21 was barely detectable $\left(<35 \mathrm{pg} \mathrm{ml}^{-1}\right)$ in BAL fluid (data not shown).

Next we checked whether viral clearance was affected. Mice primed with $\mathrm{rVV}$ - $\beta$ gal, which develop no anti-RSV memory, exhibited significant viral replication at d4 PC. Immunization reduced viral replication to undetectable levels; however, viral genome was detectable in IL-21-depleted mice, suggesting clearance had been compromised (Figure 2b). IL-21 depletion did not alter the kinetics of replication, and by $\mathrm{d} 7 \mathrm{PC}$, all mice had cleared the virus.

\section{IL-21 depletion reduces antibody production in primed, RSV-challenged mice}

As viral-specific antibody is a crucial component of long-term protective anti-viral immunity, we determined the effect of IL-21 depletion on serum RSV-specific antibody levels. Priming with RSV G protein results in weak but detectable 

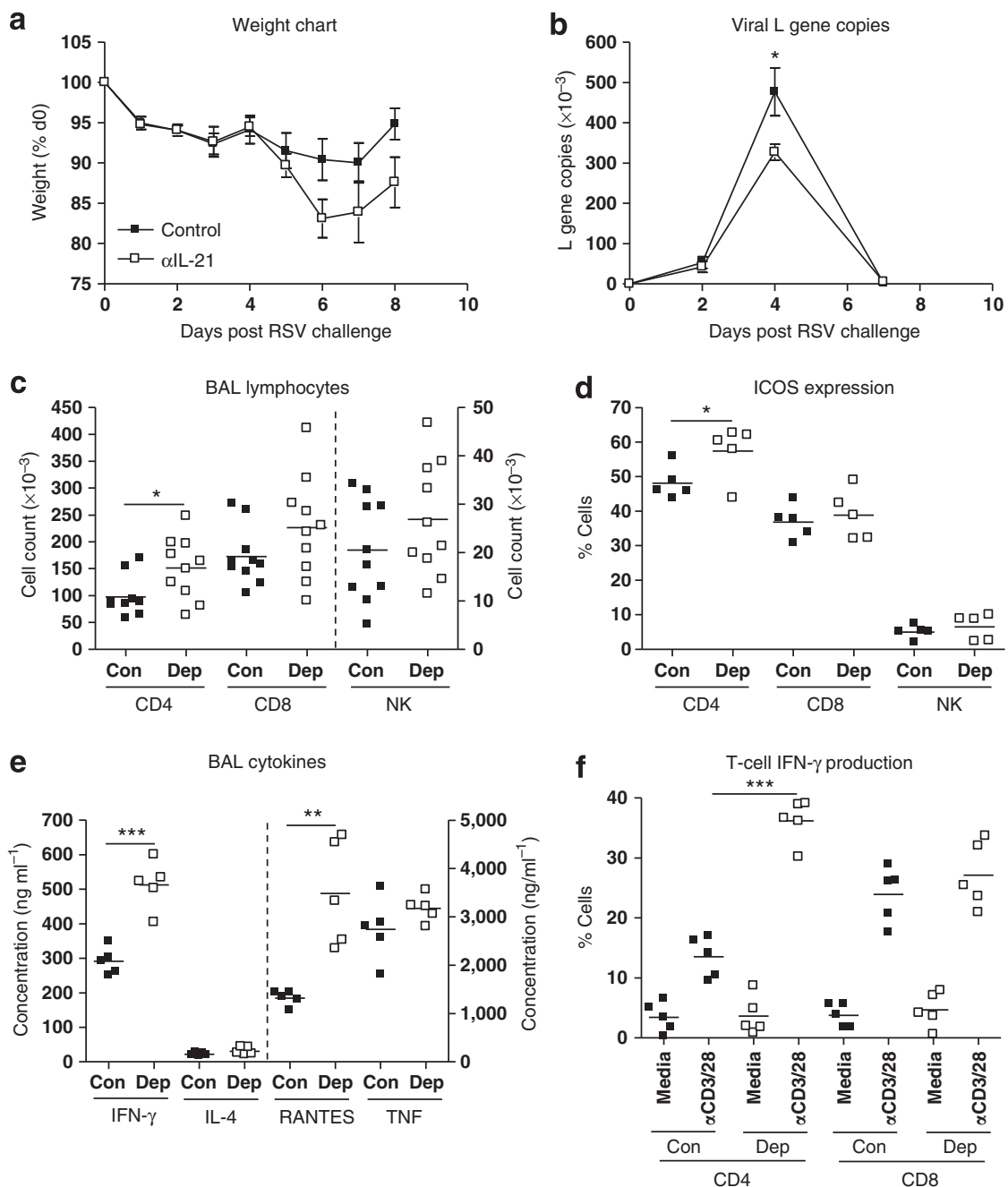

Figure 1 Interleukin-21 (IL-21) depletion increases CD4 T-cell responses to primary respiratory syncytial virus (RSV) challenge. Mice were challenged with RSV on d0 and treated with $\alpha \mathrm{lL}-21$ antibody ( $0.5 \mathrm{mg}$; intraperitoneally; Dep) or isotype control (Con) 1 day before and after challenge. (a) Mice were weighed daily, and percentage of weight loss was calculated. Lungs were harvested, processed, and RNA extracted as described in Materials and Methods. cDNA was produced by real-time reverse transcriptase-PCR and copies of the RSV L gene were determined by quantitative PCR (Taqman). Plasmids encoding the $L$ gene were used as standards to quantitate $L$ gene copies. (b) Results are expressed as the number of $L$ gene copies. Bronchoalveolar lavage (BAL) fluid and lungs were harvested at d7 post challenge. CD4 T cell, CD8 T cell, and natural killer (NK) cell recruitment into (c) BAL fluid and (d) their ICOS (inducible costimulatory molecule) expression was determined by flow cytometry. (e) Cytokines were quantitated in BAL fluid by sandwich enzyme-linked immunosorbent assay. (f) Interferon (IFN)- $\gamma$ production by lung CD4 and CD8 T cells was determined by flow cytometry. Error bars represent s.e.m. The graphs are representative of three independent experiments of five mice per group. Student's $t$-test result; ${ }^{\star} P<0.05,{ }^{* *} P<0.01,{ }^{* *} P<0.001$. RANTES, regulated and normal T cell expressed and secreted; TNF, tumor necrosis factor.

levels of RSV-specific immunoglobulin G1 (IgG1) and IgG2a (Figure 3a). No virus-specific IgA or IgE was detected (data not shown). IL-21 depletion reduced RSV-specific IgG1 levels but not IgG2a (Figure 3a). We then measured serum RSV-specific antibody $14 \mathrm{~d}$ post RSV challenge when the virus has been cleared and cellular response reduced to baseline levels. There were enhanced RSV-specific IgG1 and IgG2a levels in control mice compared with pre-RSV challenge, and IL-21 depletion significantly reduced levels of both antibody isotypes (Figure 3b).

\section{IL-21 depletion at priming boosts the number of activated lung CD4 T cells after RSV challenge}

To examine how IL-21 depletion affects CD4 T-cell differentiation, we determined FoxP3, ROR $\gamma$ t (related orphan receptor- $\gamma \mathrm{t}$ ), and T-bet expression in splenic CD4 $\mathrm{T}$ cells before RSV challenge and lung CD4 T cells at $\mathrm{d} 5 \mathrm{PC}$ (peak of disease severity). IL-21 depletion did not alter FoxP3 (Figure 4a), ROR $\gamma \mathrm{t}$ (Figure 4b), or T-bet (Figure 4c) expression by splenic CD4 $\mathrm{T}$ cells (Figure 4d) nor did it alter cell numbers (Figure 4e). However, at d5 PC, a significantly reduced proportion of BAL CD4 T cells from IL-21-depleted mice expressed FoxP3 (Figure 5a,d), while the proportion expressing ROR $\gamma \mathrm{t}$ (Figure 5b,d) or T-bet (Figure $\mathbf{5 c}, \mathbf{d}$ ) was similar. Consequently, there was an increase in total ROR $\gamma \mathrm{t}^{+}$ and T-bet ${ }^{+}$BAL CD4 T-cell numbers as a result of IL-21 depletion (Figure 5e). This trend also occurred in lung tissue (see Supplementary Figure S1 online), but there were no significant differences in the cells of the mediastinal lymph nodes (see Supplementary Figure S2 online). 

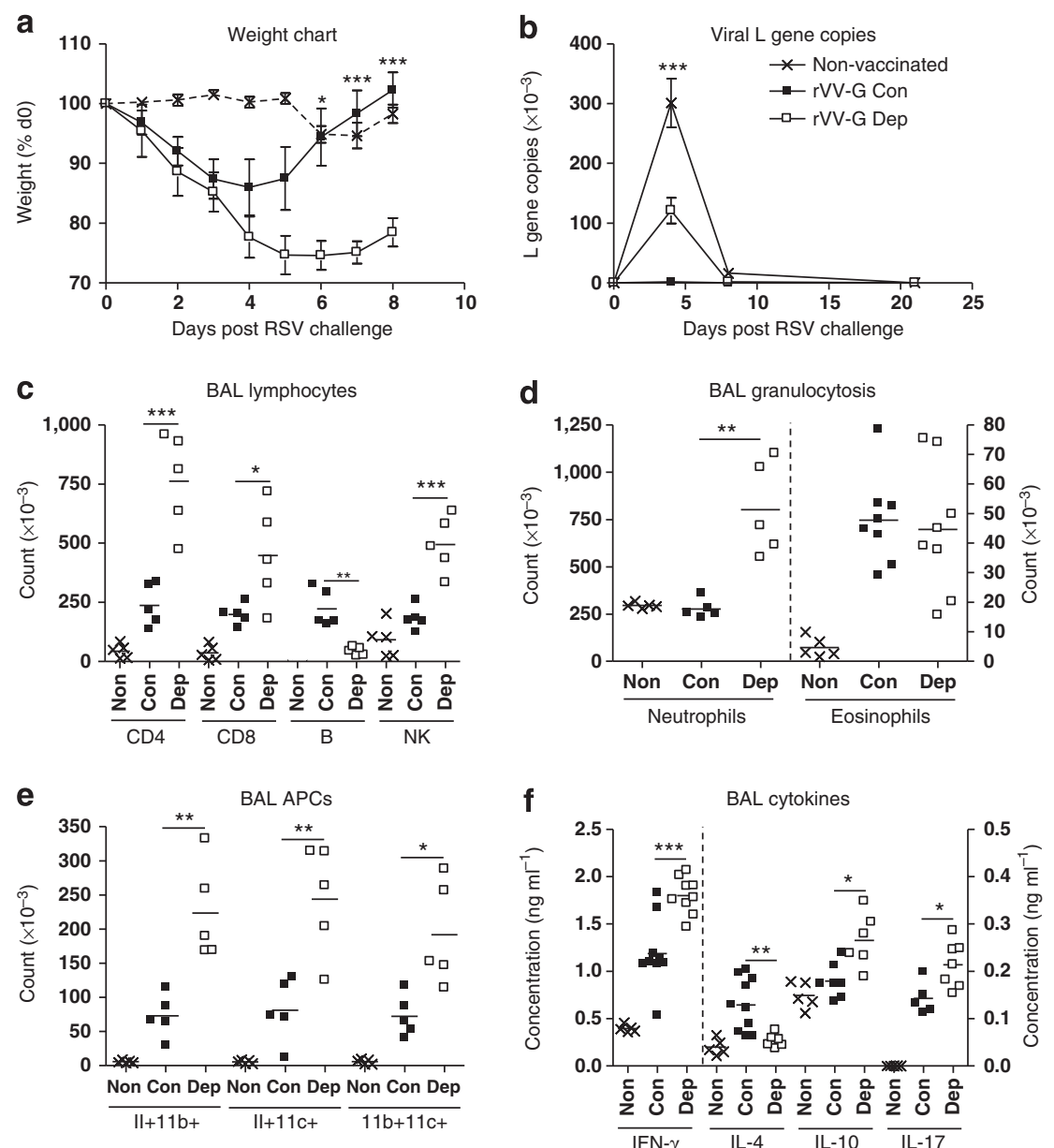

Figure 2 Interleukin-21 (IL-21) depletion exacerbates immunopathology but compromises viral clearance upon respiratory syncytial virus (RSV) challenge. Mice were immunized with vaccinia virus expressing $\beta$ gal (Non-vaccinated) or RSV G protein (rVV-G) and treated with $\alpha$ lL-21 antibody ( $0.5 \mathrm{mg}$; intraperitoneally; Dep) or isotype control (Con) 1 day before and 2 days after immunization. They were challenged with RSV 14 days later. (a) Mice were weighed daily, and percentage of weight loss was calculated. Lungs were harvested, processed, and RNA extracted as described in Materials and Methods. CDNA was produced by real-time reverse transcriptase-PCR and copies of the RSV L gene were determined by quantitative PCR (Taqman). Plasmids encoding the $L$ gene were used as standards to quantitate $L$ gene copies. (b) Results are expressed as the number of $L$ gene copies. Bronchoalveolar lavage (BAL) fluid and lungs were harvested at d5 post challenge. (c) CD4 T cell, CD8 T cell, B cell and NK cell recruitment, (d) granulocyte recruitment, and (e) antigen presenting cell recruitment into BAL fluid was determined by flow cytometry. Cytokines were quantitated in BAL fluid by sandwich enzyme-linked immunosorbent assay (f). Error bars represent s.e.m. The graphs are representative of three independent experiments of five mice per group. Analysis of variance (Tukey's post-test) or Student's $t$-test result; ${ }^{*} P<0.05,{ }^{\star \star} P<0.01,{ }^{\star \star \star} P<0.001$. APC, antigen-presenting cell; IFN, interferon; NK, natural killer.

\section{Lung CD4 T cells from rVV-G primed, IL-21-depleted mice secrete more IFN- $\gamma$ and IL-17 after RSV challenge}

As IL-21 depletion increased total numbers of $\mathrm{ROR} \gamma \mathrm{t}^{+}$and T-bet ${ }^{+}$CD4 T cells in BAL and lung, we wanted to confirm that lung CD4 T cells were producing increased levels of IL-17 and IFN- $\gamma$. Therefore, $5 \mathrm{~d}$ PC, we stimulated lung cells with either media or $\alpha \mathrm{CD} 3 / 28$ beads overnight and stained them for cytokine production the next day. There were increased percentages of $\mathrm{CD} 4 \mathrm{~T}$ cells in IL-21-depleted mice (Figure 6a). Approximately $12 \%$ of these cells from both the groups of mice produced IFN- $\gamma$ (but no IL-17) after stimulation with media alone (Figure 6b). Production of both IFN- $\gamma$ and IL-17 increased when the cells were stimulated with $\alpha \mathrm{CD} 3 / 28$ beads o/n (Figure 6c). However, lung CD4 T cells from IL-21-depleted mice produced significantly more IFN- $\gamma$ and IL-17 (both single and co-producing populations) than control cells (Figure 6d). We also determined whether there was increased production post priming in the spleen (see Supplementary Figure S3 online). There was no change in IFN- $\gamma$ production; however, there was a small but significant increase in IL-17 production in the depleted group (see Supplementary Figure S3c,d online).

\section{IL-21 depletion enhances cytokine production by lung CD4 T cells}

To determine the effect of IL-21 depletion on cytokine production by antigen-specific CD4 $\mathrm{T}$ cells, we sorted CD4 $\mathrm{T}$ cells and DCs from the lungs of rVV-G primed, control, and IL-21-depleted mice at the peak of disease (d5 PC) after RSV challenge. The DCs were pulsed with specific G peptide (p31; G184-198) or control peptide (p11; G64-78) and co-cultured with CD4 T cells. Cytokine levels in the supernatant were 

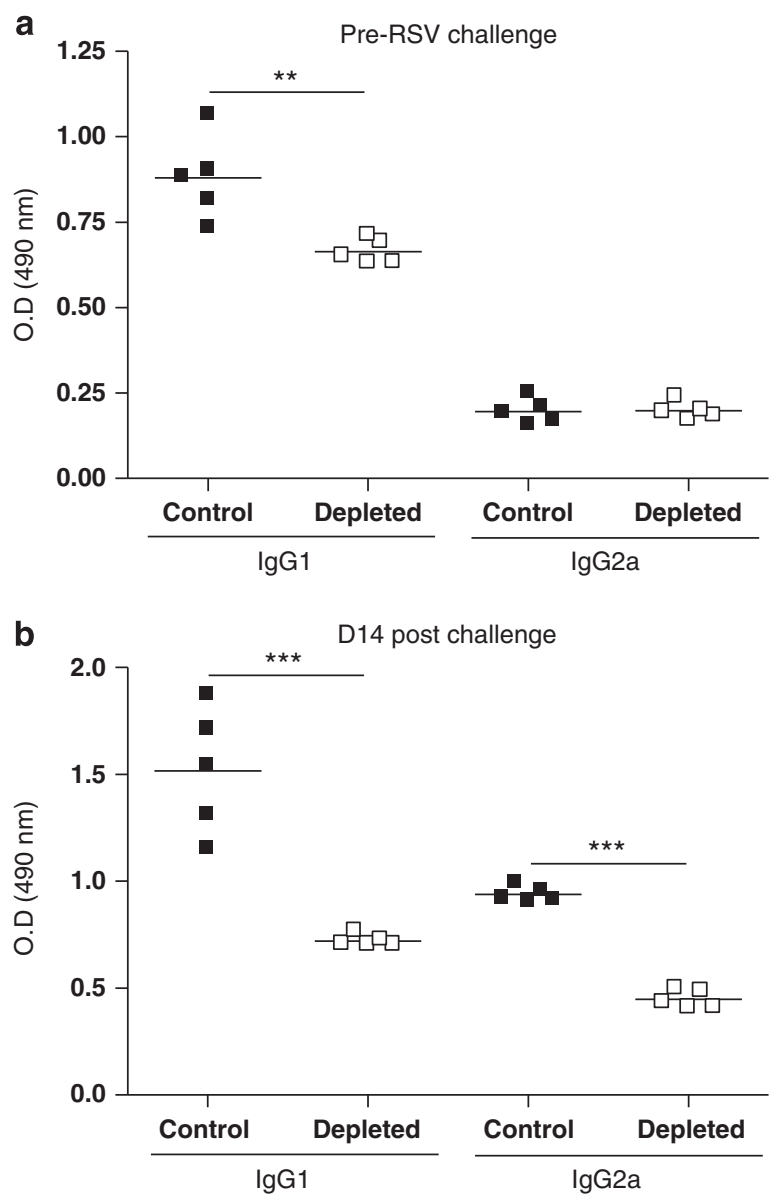

Figure 3 Interleukin-21 (IL-21) depletion decreases virus-specific antibody production. Mice were immunized and challenged as described in Figure 2. Sera from individual vaccinated mice were taken on day 14 post priming, (a) before respiratory syncytial virus (RSV) challenge or (b) 14 days post RSV challenge, and levels of RSV-specific immunoglobulin G1 (IgG1) and IgG2a were determined by enzyme-linked immunosorbent assay. The results shown are for 1:100 dilution and are representative of two independent experiments of five mice per group. Student's $t$-test result; ${ }^{* *} P<0.01,{ }^{* *} P<0.001$. OD, optical density.

determined after $72 \mathrm{~h}$ by enzyme-linked immunosorbent assay (ELISA). DCs from either group pulsed with control peptide did not elicit cytokine production by CD4 T cells (Figure 7). DCs from control mice pulsed with RSV G peptide elicited IFN- $\gamma$ (Figure 7a) and IL-21 (Figure 7c) by CD4 T cells. There was also a small but detectable IL-4 (Figure 7d), IL-10 (Figure 7b), and IL-17 (Figure 7e) response. By contrast, CD4 $\mathrm{T}$ cells from IL-21-depleted mice produced significantly more IFN- $\gamma$, IL-4, IL-10, and IL-17 upon stimulation with specific antigen. However, IL-21 was not produced by these cells, suggesting that IL-21 depletion during priming had abolished the capacity of $\mathrm{T}$ cells to produce IL-21 (Figure 7c).

\section{Adoptive transfer of CD4 T cells from rVV-G primed, IL-21-depleted, RSV-infected mice exacerbates immunopathology in recipient mice after RSV challenge} As there is no direct method by which to isolate anti-RSV-Gprotein-specific memory $\mathrm{CD} 4 \mathrm{~T}$ cells, we determined the cytokine secretion profile of G-specific cells taken $28 \mathrm{~d}$ post RSV challenge, after stimulation with specific peptide (G184198). There was no cytokine production by naive spleen cells after peptide stimulation (Figure 8). No IL-4 (Figure 8b), IL-17 (Figure 8d), or IL-21 (Figure 8f) production was detected from G-specific spleen cells from control or IL-21-depleted mice; there was weak but detectable IL-10 production (Figure 8c), but no significant difference resulting from IL-21 depletion. By contrast, there was significant IFN- $\gamma$ (Figure 8a) and granzyme $\mathrm{B}$ (Figure 8e) production by spleen cells, which was increased by IL-21 depletion in vivo. The percentage of splenic CD4 T cells expressing FoxP3 (Figure 9a), ROR $\gamma$ t (Figure 9b), T-bet (Figure 9c) did not differ significantly between the groups (Figure 9d), but IL-21 depletion in vivo increased splenic CD4 T-cell numbers so that FoxP3 ${ }^{+}, \mathrm{ROR}_{\mathrm{t}}{ }^{+}$, and T-bet ${ }^{+} \mathrm{CD} 4 \mathrm{~T}$ cells increased in total number. Moreover, there were significantly more $\mathrm{FoxP}^{+}$splenic $\mathrm{CD} 4 \mathrm{~T}$ cells from control mice compared with depleted mice (Figure 9e).

Splenic CD4 T cells from naive, control, or IL-21-depleted primed and RSV challenged mice were MACS (magnetic activation cell sorter)-sorted and adoptively transferred (intraperitoneally (IP)) into naive recipient $\mathrm{BALB} / \mathrm{c}$ mice $24 \mathrm{~h}$ before intranasal challenge with RSV. Lungs were harvested on $\mathrm{d} 7$ (PC). Transfer of naive CD4 $\mathrm{T}$ cells did not protect against disease, whereas CD4 T cells from primed, non-depleted, mice significantly reduced weight loss. By contrast, CD4 T cells from primed, IL-21-depleted mice increased the magnitude of weight loss and did not protect against the disease (Figure 10a). However, addition of G-specific CD4 $\mathrm{T}$ cells did significantly reduce viral replication compared with naive (see Supplementary Figure S4 online). Increased weight loss was associated with enhanced T-cell recruitment to the airway (Figure 10d,e). Of the CD4 $\mathrm{T}$ cells recruited to the BAL (Figure 10b) and lung (Figure 10c), most were $\mathrm{T}^{- \text {bet }^{+}}{ }^{+}$, and there were significantly more when CD4 T cells from IL-21depleted mice were administered. There was also an increase in FoxP3 ${ }^{+}$and $\mathrm{ROR} \gamma \mathrm{t}^{+}$BAL CD4 $\mathrm{T}$ cells in these mice. Significantly more CD4 (Figure 10d) and recipient CD8 (Figure 10e) $\mathrm{T}$ cells expressed an activated phenotype $\left(\mathrm{CD} 69^{+}\right.$, $\mathrm{OX}_{40}{ }^{+}$, and $\mathrm{ICOS}^{+}$) when CD4 T cells were administered from IL-21-depleted mice. CD4 T cells from IL-21-depleted mice also recruited more BAL-recipient NK cells, though their activity (as measured by CD69 expression) was identical (Figure 10f). This increase in T-bet ${ }^{+} \mathrm{CD} 4 \mathrm{~T}$ cells, CD8 T cells, and NK cells increased BAL IFN- $\gamma$ (Figure 10g) but not IL-4 levels (Figure 10h). By contrast, there was no increase in BAL IFN- $\gamma$ and a significant increase in IL-4 when control CD4 T cells were administered. BAL IL-17 levels were unaltered (Figure 10i).

To confirm whether these effects of IL-21 depletion were restricted to CD4 T cells, we performed parallel experiments in mice primed with RSV M2 protein (rVV-M2). Priming with this protein elicits a CD8 T-cell memory that is recalled to the pulmonary compartment upon RSV challenge. IL-21 depletion had less significant effects on disease severity and no significant 
a
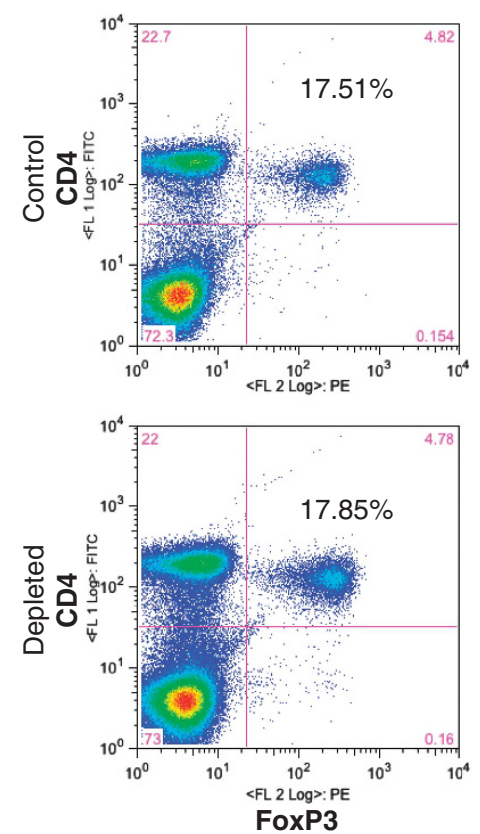

d

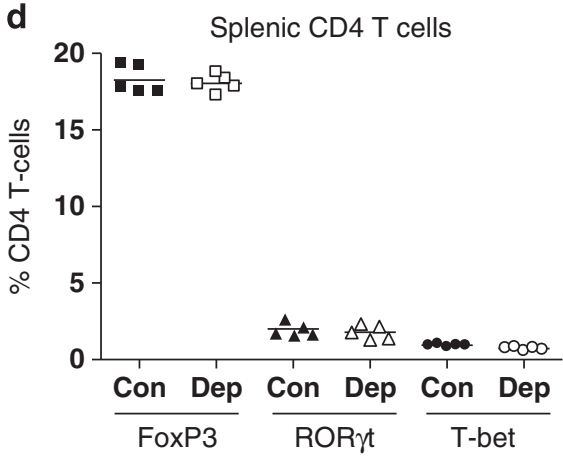

b
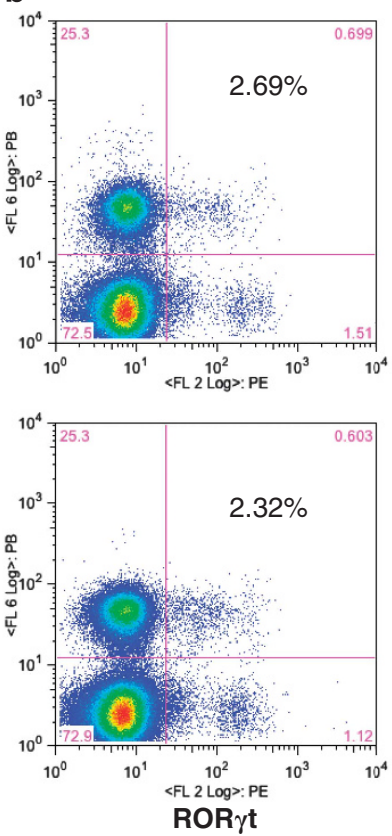

C
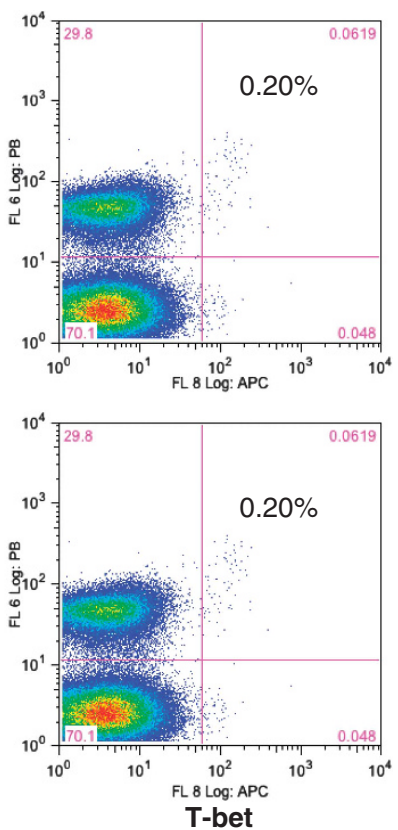

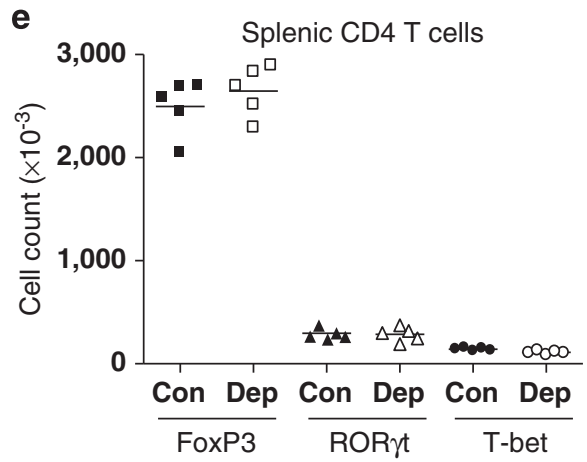

Figure 4 Interleukin-21 (IL-21) depletion has no effect on FoxP3, ROR $\gamma$ t (related orphan receptor- $\gamma \mathrm{t}$ ), and T-bet expression by splenic CD4 T cells after priming with recombinant vaccinia virus. Mice were immunized as described in Figure 2. Fourteen days post priming, spleens were harvested. CD4 T cells were stained for (a) FoxP3, (b) ROR $\gamma$ t, or (c) T-bet according to the manufacturer's instructions. The percentage of CD4 T cells expressing each transcription factor was determined by flow cytometry and is shown in each dotplot. Grouped data for (d) percentage and (e) total number are also shown. The graph is representative of two independent experiments of five mice per group. Con, control; Dep, depleted.

effect on CD8 T-cell influx into the airway or lung tissue. Moreover, there were no significant changes in immune responses between mice receiving $\mathrm{CD} 8 \mathrm{~T}$ cells from control or IL-21-depleted mice, confirming that the observed effects described in this study are limited to CD4 T cells (data not shown).

\section{DISCUSSION}

Using IL-21 depletion, we found that endogenous IL-21 skews CD4 T-cell activity: it inhibits recruitment of ROR $\gamma \mathrm{t}^{+}$and T-bet ${ }^{+}$CD4 $\mathrm{T}$ cells during RSV challenge and reduces IFN- $\gamma$ and IL-17 production. Depletion also enhanced recruitment of CD8 T cells, NK cells, and neutrophils during subsequent RSV infection, indicating an enhanced inflammation with delayed recovery. Many of these features could be transferred into naive recipients by injection of splenic CD4 T cells from IL-21depleted mice, indicating direct involvement of $\mathrm{T}$ cells programmed in the presence of IL-21 in these responses.
Although primarily anti-inflammatory, endogenous IL-21 seemed to promote clearance of RSV in vivo and enhance virus-specific serum antibody production, suggesting that IL-21 has therapeutic potential in boosting protective immunity to viral infection, while inhibiting pathological responses.

Studies of the effects of IL-21 on CD4 T-cell differentiation suggest that it has diverse actions on Th1, Th2, and Th17 lineage development. ${ }^{19,20,22}$ As we observed no change in FoxP3, ROR $\gamma$ t, or T-bet expression in splenic CD4 T cells post priming with IL-21 depletion, we infer that endogenous IL-21 does not alter CD4 T-cell differentiation under these conditions. However, we cannot rule an effect on antigen-specific CD4 T cells, as we did observe a small but significant increase in IL-17 (but not IFN- $\gamma$ ) protein upon specific CD4 T-cell stimulation in vitro (see Supplementary Figure S3 online). However, IL-21 depletion reduced the proportion of FoxP3 ${ }^{+}$ CD4 T cells post RSV challenge, correlated with an increase in 
a
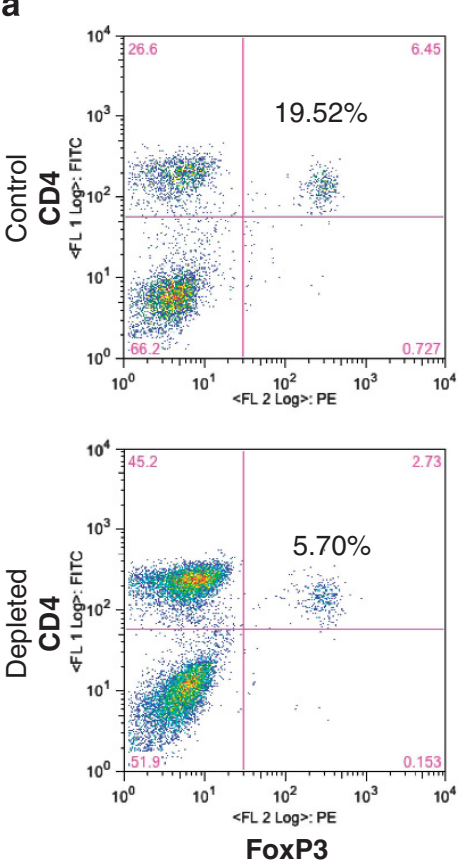

d

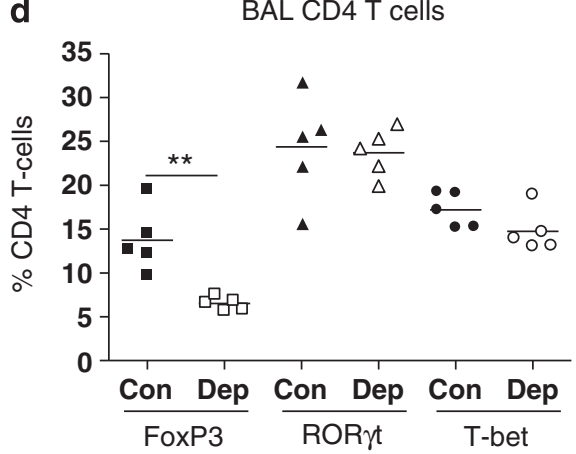

b
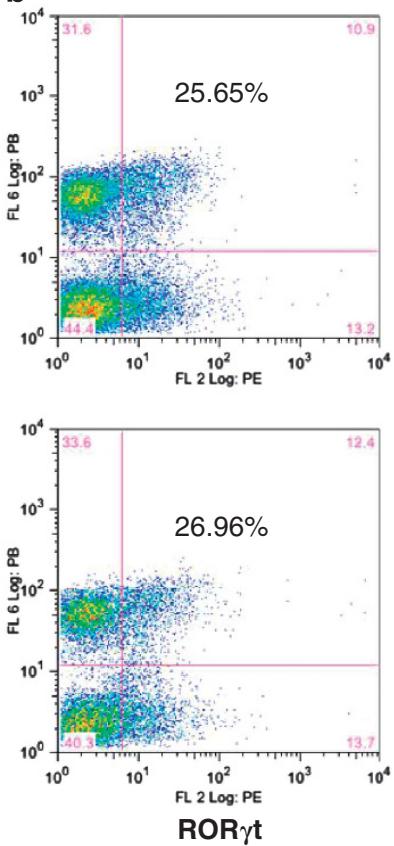

e

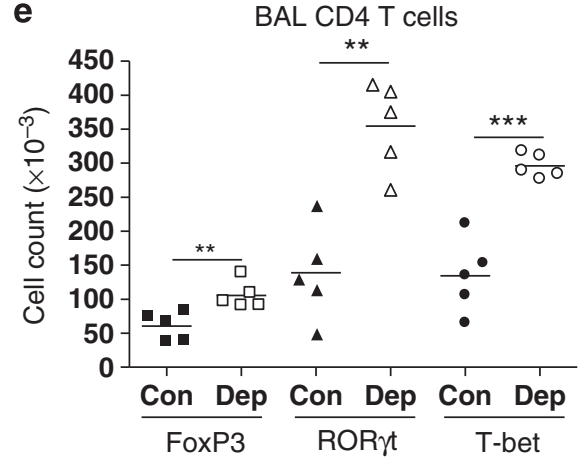

Figure 5 Interleukin-21 (IL-21) depletion in primed mice reduces FoxP3 expression by BAL CD4 T cells after respiratory syncytial virus challenge. Mice were immunized and challenged as described in Figure 2. Five days post challenge, bronchoalveolar lavage fluid (BALF) was harvested and CD4 T cells were stained for (a) FoxP3, (b) ROR $\gamma \mathrm{t}$ (related orphan receptor- $\gamma \mathrm{t}$ ), or (c) T-bet according to the manufacturer's instructions. The percentage of CD4 T cells expressing each transcription factor was determined by flow cytometry and is shown in each dotplot. Grouped data for (d) percentage and (e) total number are also shown. The graph is representative of two independent experiments of five mice per group. Student's $t$-test result; ** $P<0.01$, ${ }^{* * *} P<0.001$

disease severity. As this change was not evident in splenic CD4 $\mathrm{T}$ cells (Figure 4a), we conclude that the effects are local and specific. Therefore, IL-21 not only limits CD4 T-cell differentiation into pro-inflammatory lineages, but also aids in the development of regulatory T-cell populations to reduce pathological responses.

The consequences of the increased pro-inflammatory potential (and reduced regulatory activity) of these CD4 T cells are evident after RSV challenge. Weight loss is a reliable marker of pathology in this model, and the magnitude and kinetic of weight loss in depleted mice is greater and more prolonged than controls. The magnitude of weight loss positively correlates with the degree of cellular recruitment into the pulmonary compartment. In this study, increases in CD4 T cells and neutrophils were greatest, followed by CD8 T cells and NK cells, and finally DCs. As priming activates CD4 T cells, it is not surprising that (upon recall) their numbers would increase greatly in the event of increased activation and expansion caused by a lack of immunoregulatory IL-21. By contrast, the threefold increase in neutrophilia likely reflects an increase in chemokine levels (e.g., CXCL1) caused by a more pro-inflammatory environment. A similar mechanism may be responsible for the increase in NK cell numbers. CD8 T cells respond to RSV challenge in an antigen-specific manner, but it is likely that increased chemokine levels and increased number of $\mathrm{CD} 4 \mathrm{~T}$ cells also help contribute to their increased recruitment. Nevertheless, an effect of increased DC activation and recruitment cannot be ruled out as their recruitment increased threefold in the airway at the peak of pathology, Thus, it is likely that increased DC recruitment to the airway will result in increased T-cell activity and cytokine production. IL21 reduces MHCII expression on DC, thereby reducing their 

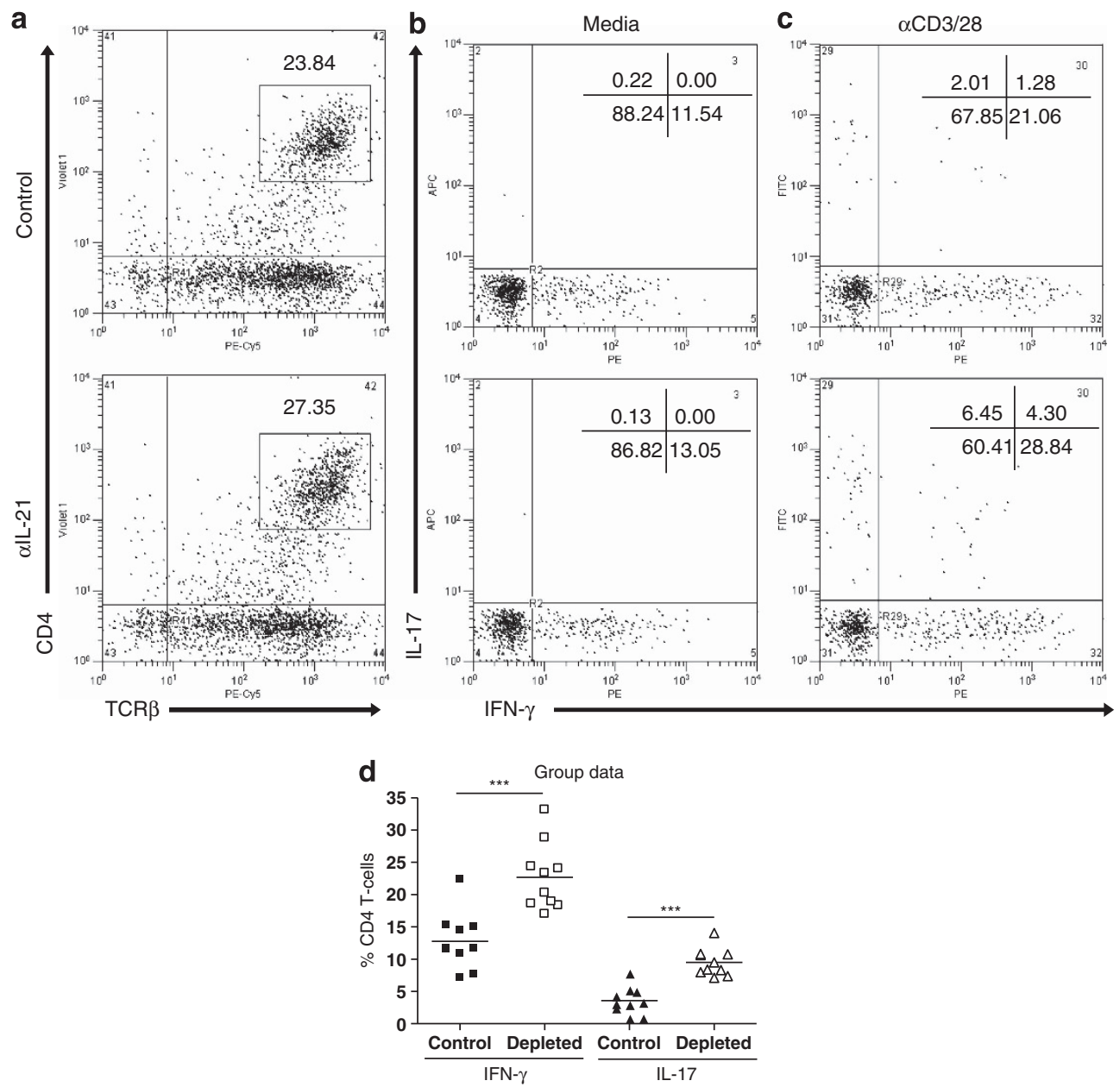

Figure 6 Interleukin-21 (IL-21) depletion increases interferon (IFN)- $\gamma$ and IL-17 production by lung CD4 T cells. Mice were immunized and challenged as described in Figure 2. Five days post challenge, lungs were harvested. CD4 T cells were sorted by magnetic activation cell sorter and stimulated overnight with (b) media or (c) $\alpha \mathrm{CD} 3 / 28$ beads $\left(10 \mu \mathrm{l}\right.$ per $10^{6}$ cells). (a) CD4 T cells were stained for IFN- $\gamma$ and IL-17 using specific catch and detection reagents $\left(10 \mu \mathrm{l}\right.$ per $10^{6}$ cells). The percentage of CD4 T cells secreting each cytokine was determined by flow cytometry and is shown in each dotplot. (d) Grouped data are also shown. The graphs are representative of two independent experiments of five mice per group. Student's $t$-test result; ${ }^{* * *} P<0.001$. TCR, T-cell receptor.

ability to activate CD4 T cells. ${ }^{36}$ This is supported by DC/CD4 $\mathrm{T}$-cell co-culture, demonstrating that $\mathrm{CD} 4 \mathrm{~T}$ cells from depleted mice produced more cytokine than control cells. The increase in cytokine production in a subset-independent manner further suggests that IL-21 is an anti-inflammatory cytokine and not subset-biasing. Despite this, no increase of IL- 4 was observed in the airway of depleted mice. This indicates that CD4 T-cell activation alone does not determine the IL-4 level in the airway, and that other factors in the environment also contribute. This may include IFN- $\gamma$-producing NK cells and CD8 T cells that would reduce IL- 4 and Th2 cytokine secretion, as was observed in the adoptive transfer experiments. B cells may also be an IL-4 source, ${ }^{37}$ and their reduction both in this study and in previous RSV disease studies with strong Th1 cytokine profiles also indicates them as a source. ${ }^{38}$

Our data indicate an increase in Th1/Th17 pathological responses in depleted mice. The increase in IL-10 may reflect self-regulation by activated $\mathrm{T}$ cells, the importance of which has been highlighted in RSV disease recently. ${ }^{39}$ The increase in
IL-10 was not associated with increased FoxP3 cell numbers, which was actually reduced at this time. The increase in lung $\mathrm{CD} 4 \mathrm{~T}$ cells from depleted mice expressing T-bet, ROR $\gamma \mathrm{t}$, and producing IFN- $\gamma$ and IL-17 correlates with the increased pathology, and cells making these mediators may be pathogenic in RSV disease. ${ }^{7}$ Indeed, CD4 T-cell transfer into naive recipient mice failed to protect against pathology upon viral challenge. This failure was associated with increased CD4 T-cell recruitment and increased IFN- $\gamma$ production, similar to the phenotype observed during primary infection and in the recall response of primed mice.

Viral clearance is associated with strong cellular immune responses; however, in this study, we observed a compromised anti-viral response. This is likely due to the reduction in antiviral serum antibody levels, indicative of reduced B-cell activity. The reduced B-cell recruitment to the airway supports this. The reduction in viral replication during primary RSV infection and adoptive transfers is likely due to enhanced lymphocytosis as no virus-specific antibody is present at this time. Several studies 


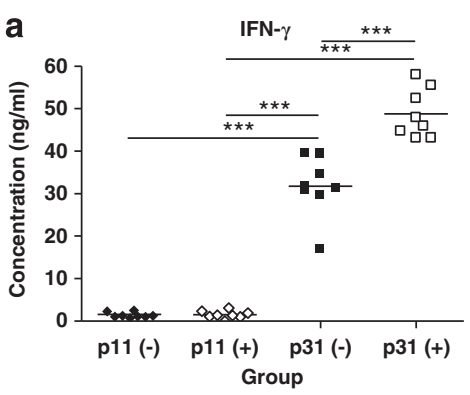

b
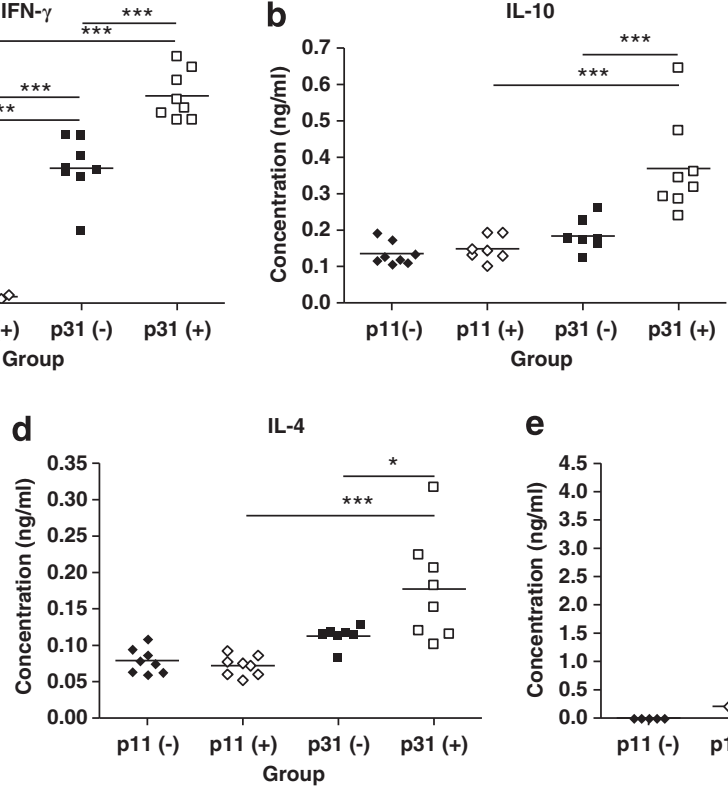

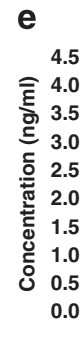

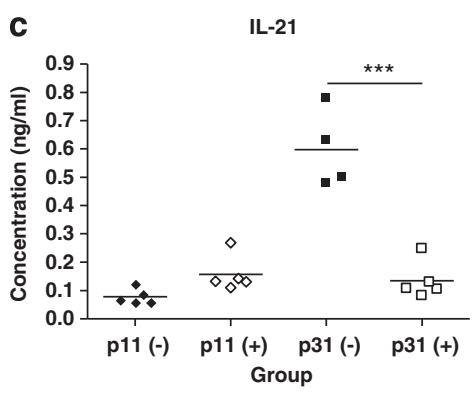

IL-17

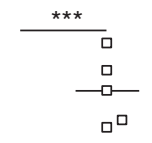

Figure 7 Interleukin-21 (IL-21) depletion increases cytokine production by antigen-specific CD4 T cells. Mice were immunized and challenged as described in Figure 2 (" -": Isotype control, "+ " anti-IL-21). Five days post challenge, lungs were harvested. CD4 T cells were sorted by magnetic activation cell sorter and dendritic cells (DCs) sorted by fluorescent-activated cell sorter. DCs $\left(4 \times 10^{4}\right.$ cells per well) were pulsed with specific (G184-198; p31) peptide or control (G64-78; p11) peptide $\left(10 \mu \mathrm{gl}^{-1}\right)$ for $1 \mathrm{~h}$ before co-culture with CD4 T cells $\left(4 \times 10^{5}\right.$ cells per well). Cells were incubated for $72 \mathrm{~h}$, the supernatants were harvested, and (a) interferon (IFN)- $\gamma$, (b) IL-10, (c) IL-21, (d) IL-4, and (e) IL-17 levels were determined by sandwich enzyme-linked immunosorbent assay. The graphs are representative of three independent experiments of five mice per group. Student's $t$-test result; ${ }^{*} P<0.05,{ }^{* \star *} P<0.001$.

have demonstrated a crucial role for IL-21 on both B-cell activation $^{40}$ and cells crucial for their activation (e.g., follicular T helper (Tfh) cells ${ }^{10,41}$ ). Early studies demonstrated that IL-21 was crucial for development of antibody-secreting plasma cells ${ }^{42}$ and suggest a crucial role for Tfh-derived IL-21 in antibody production. ${ }^{43}$ More recent studies show that IL-21 enhances Bcl-6-mediated Tfh-cell development ${ }^{41,44}$ and has a critical role in germinal center formation. ${ }^{45,46}$ Our present studies show that IL-21 is crucial for optimal antibody production and that its depletion is detrimental to shortand long-term protection against viral challenge.

Our studies contrast with a recent report of studies of pneumovirus of mice (PVM). ${ }^{47}$ Although PVM and RSV are similar virologically, PVM induces much more severe disease. The studies of PVM show that IL-21RKO mice exhibit reduced disease, cell recruitment, and chemokine/cytokine production; moreover, mice that constitutively overexpress IL-21 suffer enhanced disease, with increased recruitment and boosted chemokine/cytokine production. These studies were in C57Bl/6 mice rather than $\mathrm{BALB} / \mathrm{c}$, and genetic background is known to be important in many immunological responses. In addition, the effects of transient mediator depletion during priming are likely to differ from the effects of life-long genetic deletion, in which compensatory mechanisms occur.

In conclusion, our findings show that IL-21 has a key role in limiting the magnitude and regulating the phenotype of virusspecific CD4 T- and B-cell responses and in anti-viral immunity in RSV disease. These new insights extend our understanding of the role of IL-21, which has not previously been shown to be involved in defense against respiratory infection. Together with previous studies, our findings highlight the inherent complexity of IL-21's functions in respiratory disease. Moreover, given the genetic heterogeneity of the human population, further research is warranted to fully understand the immune function of IL-21 in the respiratory tract. Based on our findings, we speculate that IL-21 has therapeutic potential, and co-administration with vaccine antigens might be particularly effective at inducing protective immune responses in infancy, when IL-21 responses are impaired. $^{29}$

\section{METHODS}

Virus and mice. HEp-2-cell-grown plaque-purified A2 strain of RSV was snap frozen and assayed for infectivity. ${ }^{38} \mathrm{rVV}-\mathrm{G}$ (a kind gift of Gail Wertz, USA) was stored at $-80^{\circ} \mathrm{C}$. All virus preparations were free of mycoplasma (Gen-Probe, San Diego, CA).

Eight-week-old female BALB/c mice were purchased from Harlan Olac (Bicester, UK) and kept in specific pathogen-free conditions. All protocols used in this study were reviewed and approved by ethics, safety, and regulatory committees.

Mouse infection and treatment. For skin infection, rumps were shaved, decornified, and infected with rVV-G $\left(10 \mu \mathrm{l}, 10^{6} \mathrm{pfu}\right) .^{38}$ Some mice were treated (IP) with $0.5 \mathrm{mg}$ anti-IL-21 polyclonal (a kind gift of Kresten Skak from Novo Nordisk, Denmark) or isotype control antibody in $0.5 \mathrm{ml}$ phosphate-buffered saline (PBS), $1 \mathrm{~d}$ before and $2 \mathrm{~d}$ after immunization. For challenge, mice were anesthetized and infected intranasally with $100 \mu \mathrm{l}\left(5 \times 10^{5} \mathrm{pfu}\right)$ of RSV. Mice were weighed daily thereafter.

The in vivo neutralizing activity of the anti-IL-21 polyclonal antibody was confirmed before use. First, we measured total serum IgG 

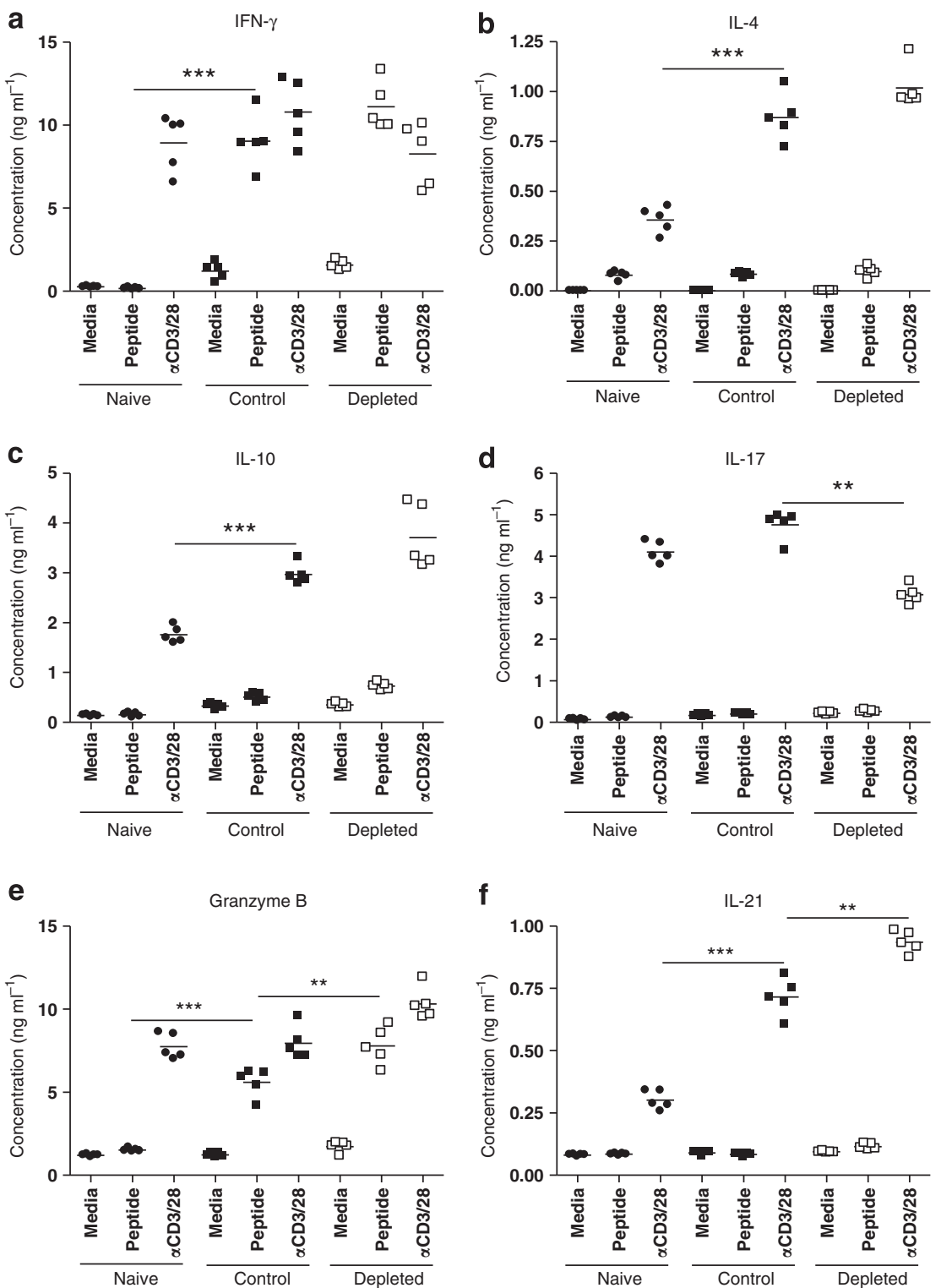

Figure 8 Interleukin-21 (IL-21) depletion at priming increases interferon (IFN)- $\gamma$ and granzyme B production by splenic CD4 T cells 28 days post respiratory syncytial virus challenge. Mice were treated as in Figure 2. Twenty-eight days post challenge, spleen cells from both the groups plus naive mice were harvested and processed. Spleen cells $\left(2 \times 10^{6}\right.$ cells per well) were stimulated with media, specific G peptide (10 $\left.\mu \mathrm{g} \mathrm{ml}{ }^{-1}\right)$, or $\alpha \mathrm{CD} 3 /$ 28 -expressing beads $(50 \mu \mathrm{l}$ per well) for $72 \mathrm{~h}$. The supernatants were harvested, and (a) IFN- $\gamma$, (b) IL-4, (c) IL-10, (d) IL-17, (e) granzyme B, and (f) IL-21 levels were determined by sandwich enzyme-linked immunosorbent assay. The graphs are representative of two independent experiments of five mice per group. Student's $t$-test result; ${ }^{\star *} P<0.01,{ }^{\star * \star} P<0.001$.

by ELISA in mice treated on d0, 2, 4, and 6 with vehicle or rmIL-21 (10 ng per dose; intranasally). rmIL-21 significantly increased total serum IgG levels, and this was ablated by treatment on $\mathrm{d}(-1)$ and $\mathrm{d}(+2)$ with anti-IL-21 antibody $(0.5 \mathrm{mg}$; IP) but not control antibody (see Supplementary Figure S5a online).

We also determined the time after administration that anti-IL-21 antibody remained effective. rmIL-21 was administered as previously described, anti-IL-21 (or control) antibody given on d0 (0.5 mg; IP), and total serum antibody levels were determined on $\mathrm{d} 0,3$, and 6 . We found that anti-IL-21 antibody reduced rmIL-21-mediated increases in total serum IgG on $\mathrm{d} 3$, but by d6 antibody levels had returned to $\mathrm{d} 0$ levels (see Supplementary Figure S5b online). This confirmed that the anti-IL-21 antibody was effective for up to $6 \mathrm{~d}$ in vivo.

Cell recovery. After killing by IP injection of $3 \mathrm{mg}$ of pentobarbital, BAL fluid, lung tissue, spleen, and serum were harvested. ${ }^{38}$ In brief, the lungs were inflated twice with $1 \mathrm{ml}$ of $12 \mathrm{~mm}$ lidocaine in Earle's Balanced Salt Solution and kept on ice. The BAL fluid was centrifuged, the supernatant removed, and stored at $-80^{\circ} \mathrm{C}$. Pelleted cells were resuspended in RPMI with $10 \%$ fetal calf serum, $2 \mathrm{~mm} \mathrm{ml}^{-1}$ glutamine, $50 \mathrm{U} \mathrm{ml}^{-1}$ penicillin, and $50 \mathrm{mg} \mathrm{ml}^{-1}$ streptomycin ("R10F”). The cell suspension was passed through a $100-\mu \mathrm{m}$ filter (Sartorius, Epsom, UK) and red blood cells lysed with ACK (ammonium chloridepotassium) buffer. The cells were washed, resuspended in R10F, and live cells counted using trypan blue.

Quantification of viral replication and gene expression. Total RNA was extracted and stored in cell lysis and RNA stabilisation RLT buffer (Qiagen, Crawley, UK). In all, $1 \mu \mathrm{g}$ total RNA was used to synthesize cDNA using random hexanucleotides in $20 \mu \mathrm{l}$. Viral L gene copies were measured against standard plasmids $\left(10^{7}-10^{1}\right.$ copies $)$ and a non-template controls. Also, $100 \mathrm{ng}$ cDNA was used per reaction with forward primer 

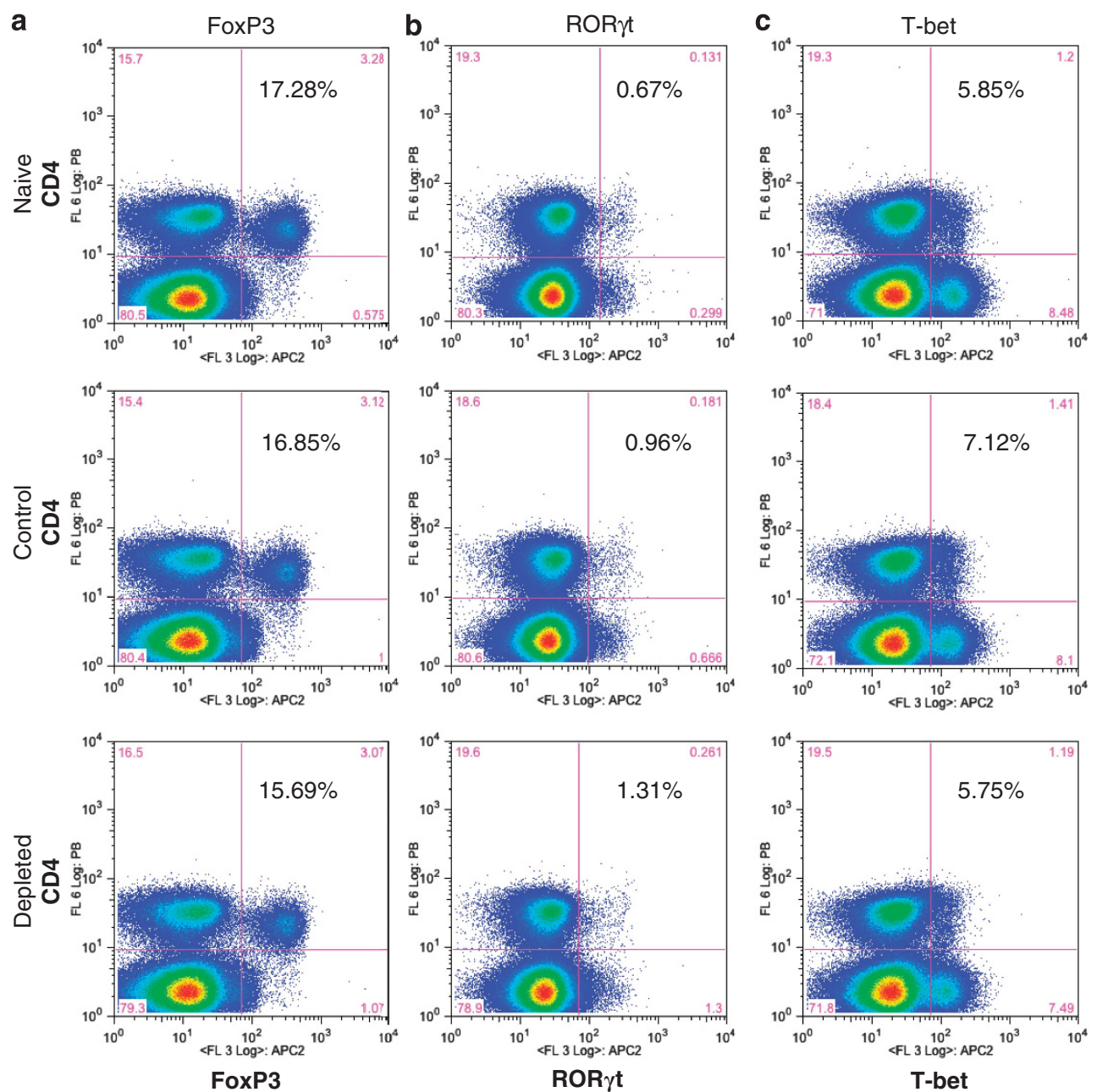

d
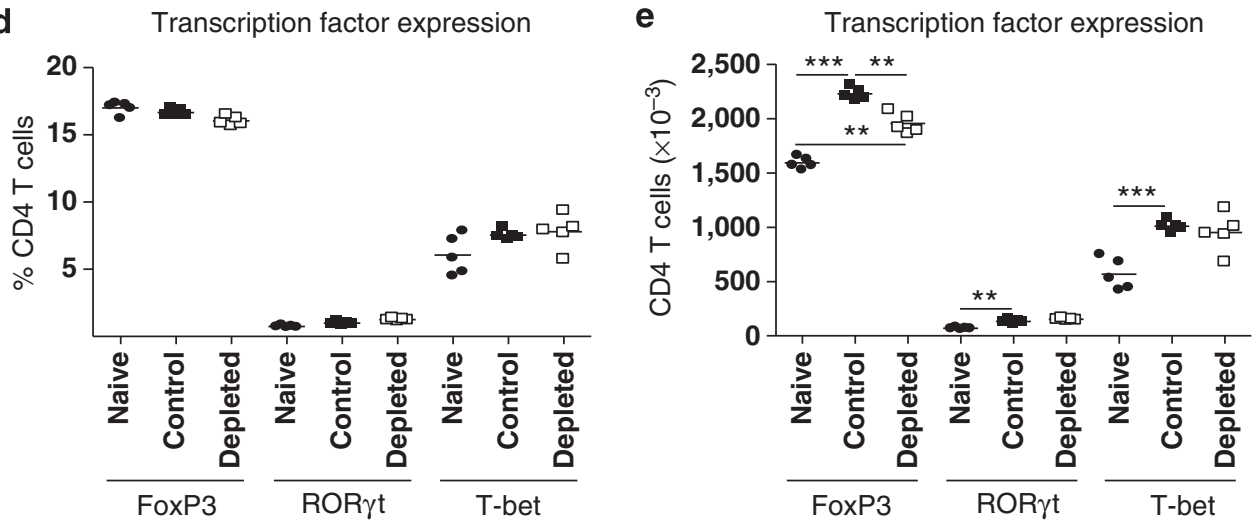

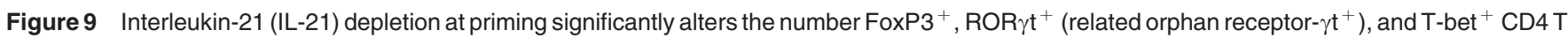
cells 28 days post respiratory syncytial virus challenge. Mice were treated as in Figure 2. Twenty-eight days post challenge, spleen cells from both the groups plus naive mice were harvested and processed. CD4 T cells were stained for (a) FoxP3, (b) ROR $\gamma$ t, or (c) T-bet according to the manufacturer's instructions. The percentage of CD4 T cells expressing each transcription factor was determined by flow cytometry and is shown in each dotplot. Grouped data for (d) percentage and (e) total number are also shown. The graph is representative of two independent experiments of five mice per group. Student's $t$-test result; ${ }^{* \star} P<0.01,{ }^{* \star \star} P<0.001$.

$(900 \mathrm{~nm})$, reverse primer $(300 \mathrm{nM})$, and probe $(100 \mathrm{~nm})$ in $20 \mu \mathrm{l}$ total volume, using 1 cycle of $50^{\circ} \mathrm{C}$ for $2 \mathrm{~min}, 1$ cycle of $95^{\circ} \mathrm{C}$ for $10 \mathrm{~min}, 1$ cycle of $95^{\circ} \mathrm{C}$ for $15 \mathrm{~s}$, and 1 cycle of $60^{\circ} \mathrm{C}$ for $60 \mathrm{~s}$ on a ABI 7500 Taqman Cycler (Applied Biosystems, Warrington, UK). The final two stages are repeated 45 times in sequence. For gene expression, $100 \mathrm{ng}$ cDNA was used per reaction with specific primer/probe sets and mastermix from Applied Biosystems (used according to the manufacturer's instructions). Total volume and reaction set up was used as for viral $\mathrm{L}$ gene analysis above. Gene expression was measured as an RQvalue $\left(2^{-\Delta \Delta C t}\right)$ calculated using Sequence Detection software v1.4 (Applied Biosystems). 

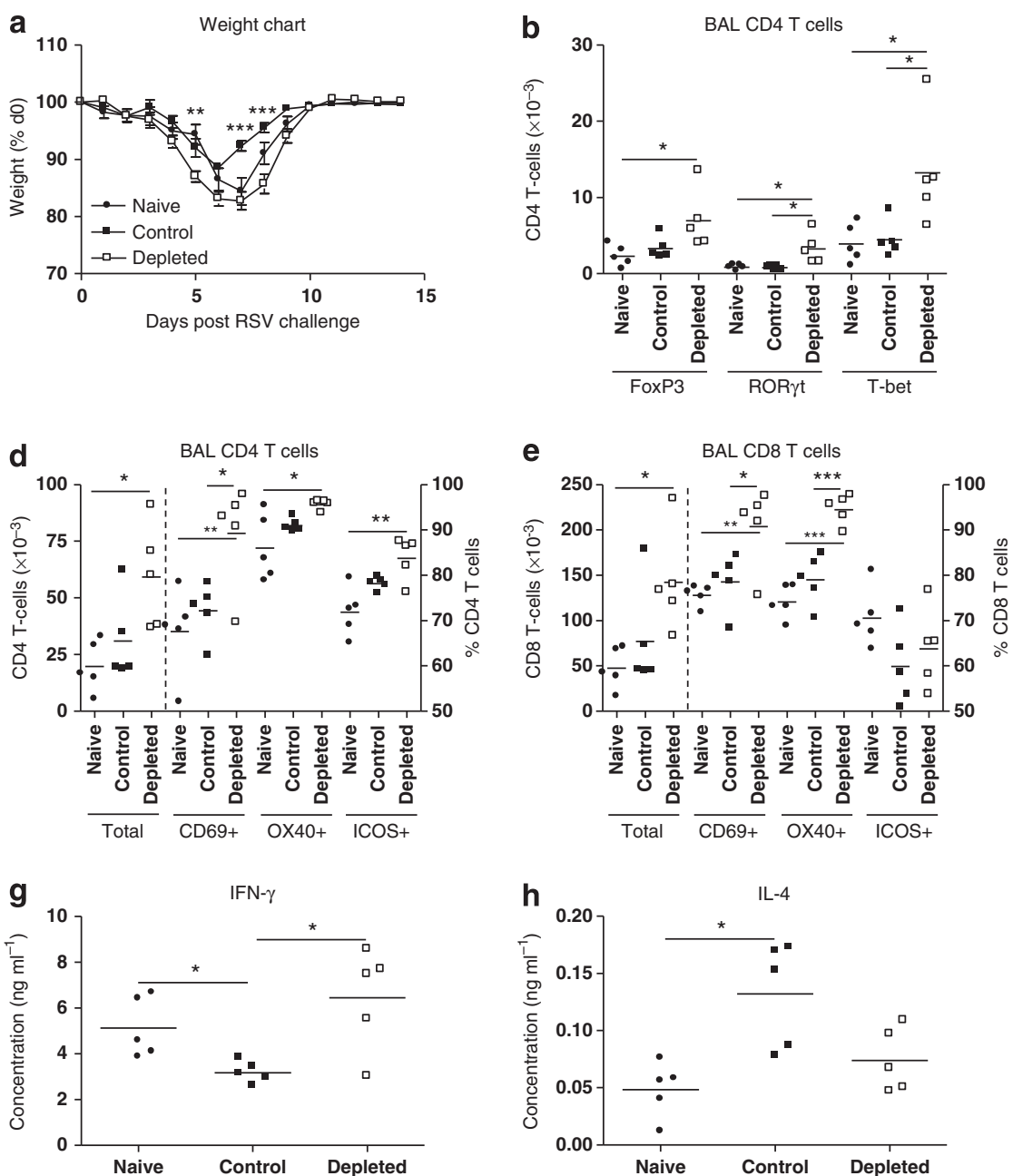
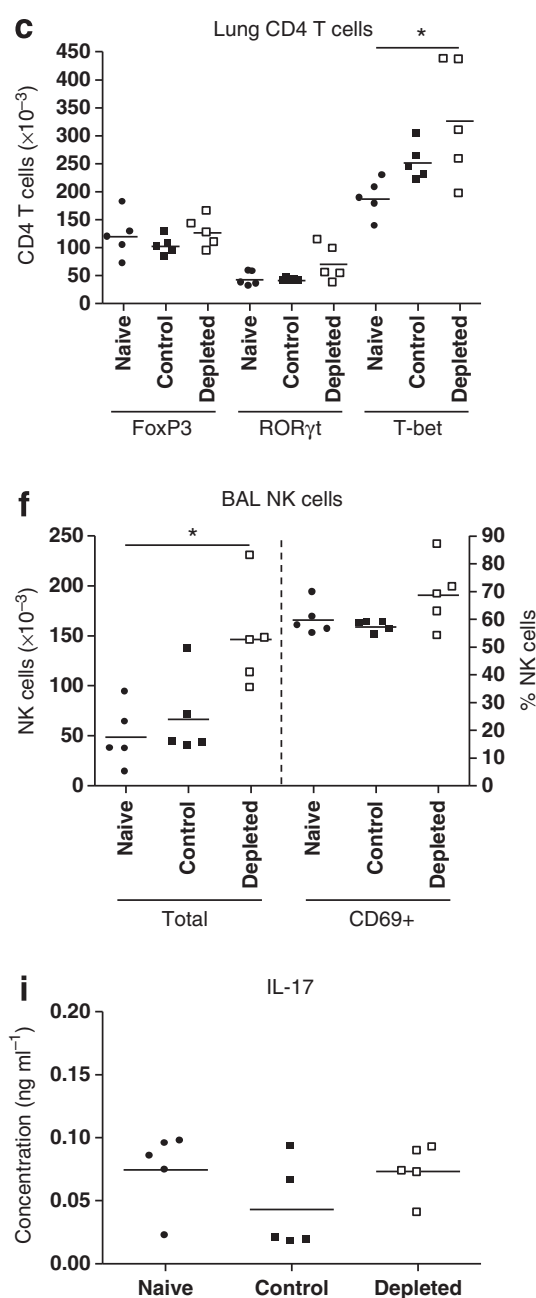

Figure 10 Adoptive transfer of CD4 T cells from interleukin-21 (IL-21)-depleted mice exacerbates pathology in recipient mice upon respiratory syncytial virus (RSV) challenge. Mice were treated as in Figure 2. Twenty-eight days post challenge, splenic CD4 T cells were MACS (magnetic activation cell sorter)-sorted and $2 \times 10^{6}$ cells per mouse were transferred (intraperitoneally) into naive recipients 1 day before RSV infection. Naive T cells were sorted and transferred into a third group as a control. (a) Weights were measured daily for 14 days. Seven days post challenge, bronchoalveolar lavage (BAL) fluid and lungs were harvested. The number of FoxP3 ${ }^{+}, \mathrm{ROR}_{\gamma \mathrm{t}^{+}}$(related orphan receptor- $\gamma \mathrm{t}^{+}$), and T-bet ${ }^{+} \mathrm{CD} 4 \mathrm{~T}$ cells in (b) BAL and (c) lung were determined by flow cytometry. Recruitment and activity of (d) CD4 T cells, (e) CD8 T cells, and (f) natural killer (NK) cells to the BAL were determined by flow cytometry using specific markers. (g) Interferon (IFN)- $\gamma$, (h) IL-4, and (i) IL-17 levels in BAL fluid were determined by sandwich enzyme-linked immunosorbent assay. The graphs are representative of three independent experiments of five mice per group. Analysis of variance (Tukey's post test) result; ${ }^{\star} P<0.05,{ }^{\star \star} P<0.01$, ${ }^{\star \star \star} P<0.001$. ICOS, inducible costimulatory molecule.

Staining and flow cytometric analysis of surface and intracellular antigens. Cellular phenotyping was performed on BAL, lung, and spleen cells by flow cytometry as described. ${ }^{38}$ Briefly, cells were transferred into 96-well, v-bottomed plates and washed in FACS (fluorescent-activated cell sorter) staining buffer (PBS/bovine serum albumin $\left.(1 \% \mathrm{w} / \mathrm{v}) / \mathrm{NaN}_{3}(0.1 \% \mathrm{w} / \mathrm{v})\right) . \mathrm{F}_{\mathrm{c}} \gamma$ receptors were blocked using $\alpha \mathrm{CD} 16 / 32$ antibodies, and cells were stained using antibodies against multiple cell markers. All antibodies were purchased from Biolegend (London, UK) unless otherwise stated and used at pre-optimized concentrations. After staining (except for transcription factor expression, see below), cells were washed in PBS and fixed using paraformaldehyde ( $4 \% \mathrm{v} / \mathrm{v})$ for $20 \mathrm{~min}$. Cells were washed and resuspended in FACS staining buffer and taken for analysis. At least $40 \times 10^{3}$ cells from each sample were collected on a Dako Cyan flow cytometer (Ely, UK). Analysis was performed using Winlist6.0 (Verity, Topsham, ME).

For transcription factor expression, cells were washed in PBS and fixed and permeabilized using a solution containing paraformaldehyde/saponin (eBioscience, Hatfield, UK) overnight at $4{ }^{\circ} \mathrm{C}$. Cells were then washed in permeablisation buffer (eBioscience) and incubated in the same buffer $(50 \mu \mathrm{l}$ per well) for $15 \mathrm{~min}$. Cells were then stained for FoxP3, ROR $\gamma$ t, or T-bet (1:200 dilution; eBioscience) by adding permeablisation buffer $(50 \mu \mathrm{l}$ per well) containing relevant antibodies and incubated for $45 \mathrm{~min}$ at $4^{\circ} \mathrm{C}$. Cells were washed in permeabilisation buffer and closed by washing with FACS buffer. Cells were resuspended in FACS staining buffer and taken for analysis. At least $100 \times 10^{3}$ cells from each sample were collected on a Dako Cyan flow cytometer. Analysis was performed using Winlist6.0 (Verity).

In vitro cytokine production by lung or spleen CD4 T cells. Lungs were harvested and processed as described above. Cells were counted using trypan blue exclusion assay, set up in 48 -well plates $\left(2 \times 10^{6} \mathrm{per}\right.$ well), and stimulated with media, RSV (multiplicity of infection 2.0), or $\alpha \mathrm{CD} 3 / \alpha \mathrm{CD} 28$-coated beads (Invitrogen, Paisley, UK; pre-titrated to $10 \mu \mathrm{l}$ stock per $10^{6}$ cells) at $37^{\circ} \mathrm{C} / 5 \% \mathrm{CO}_{2}$ overnight. Next day, supernatants were harvested and stored at $-80^{\circ} \mathrm{C}$ before analysis of cytokine levels by ELISA. The cells were washed in FACS staining buffer, and capture reagents for IFN- $\gamma$, IL-4, IL-10, and IL-17 (Miltenyi Biotec Cytokine Secretion assay (Bisley, UK); $10 \mu \mathrm{l}$ per $10^{6}$ cells; diluted 
in cold RPMI) were added to each well. Cells were incubated at $4{ }^{\circ} \mathrm{C}$ for $15 \mathrm{~min}$ before addition of $1 \mathrm{ml}$ warm media and incubation at $37^{\circ} \mathrm{C} /$ $5 \% \mathrm{CO}_{2}$ for $1 \mathrm{~h}$ to allow cytokine release from cells. Cells were then washed in FACS staining buffer and stained with detection reagents (Miltenyi Biotec Cytokine Secretion assay; $10 \mu \mathrm{l}$ per $10^{6}$ cells; diluted in cold FACS staining buffer) for IFN- $\gamma$-phycoerythrin, IL-4-phycoerythrin, IL-10-allophycocyanin, and IL-17-allophycocyanin. $\alpha$ TCR $\beta$ QR and $\alpha C D 4$-PacBlue or $\alpha$ CD8-PacBlue antibodies were also added at pre-optimized concentrations to identify CD4 or CD8 T cells. Cells were then washed in FACS staining buffer before analysis. At least $100 \times 10^{3}$ cells from each sample were collected on a Dako Cyan flow cytometer. Analysis was performed using Winlist6.0 (Verity).

Spleen cells were harvested and processed as lung cells. Cells were counted using trypan blue exclusion assay, set up in 48-well plates $\left(2 \times 10^{6}\right.$ per well), and stimulated with media, specific $G$ peptide (G184-198; $10 \mu \mathrm{g} \mathrm{ml}^{-1}$ ), or $\alpha \mathrm{CD} 3 / \alpha \mathrm{CD} 28$-coated beads (Invitrogen; pre-titrated to $10 \mu \mathrm{l}$ stock per $10^{6}$ cells) at $37^{\circ} \mathrm{C} / 5 \% \mathrm{CO}_{2}$ for $72 \mathrm{~h}$. Supernatants were harvested and stored at $-80^{\circ} \mathrm{C}$ before analysis of cytokine levels by ELISA.

In vitro cytokine production from sorted DCs and CD4 T cells. Lung cells from control or IL-21-depleted mice were harvested and processed as described above. CD4 T cells from both the groups were MACS-sorted using a positive isolation kit (Miltenyi Biotech, Bisley, UK). DCs were FACS-sorted from the remaining cells by staining using $\alpha$ CD11c-FITC and $\alpha$ CD11b-phycoerythrin antibodies and collected positively stained cells on a FACS Diva sorter. DC purity of $>93 \%$ was obtained. Collected DCs were washed, counted, set up at $4 \times 10^{4}$ per well, and pulsed with a non-specific RSV G-negative control peptide (p11: G64-78) or antigen-specific peptide (p31: G184$\left.198 ; 10 \mu \mathrm{g} \mathrm{ml}^{-1}\right)$. Sorted CD4 T cells $\left(4 \times 10^{5}\right.$ cells per well $)$ were added and cultured in $200 \mu \mathrm{l} \mathrm{R} 10 \mathrm{~F}$ medium in 96-well, round-bottomed plates. After $72 \mathrm{~h}$, the supernatants were harvested and stored at $-80^{\circ} \mathrm{C}$ for cytokine analysis later. IFN- $\gamma$, IL- 4 , IL-10, IL-17, and IL-2 1 were quantified as described below.

Cytokine ELISA. Cytokine levels were quantified using paired antibodies from R\&D Systems (Abingdon, UK; following the manufacturer's instructions) unless otherwise stated. In brief, microtiter plates were coated with $100 \mu \mathrm{l}$ (1:200 dilution) of capture antibody overnight at $4{ }^{\circ} \mathrm{C}$. After three washes with PBS containing $0.5 \%$ Tween20 , plates were blocked with $200 \mu \mathrm{l}$ of PBS-1\% bovine serum albumin and left for $2 \mathrm{~h}$ at room temperature. Samples and standards (diluted in PBS with $1 \%$ bovine serum albumin and $0.05 \%$ Tween 20 ) were incubated overnight at $4{ }^{\circ} \mathrm{C}$. After four washes, bound cytokine was detected using biotinylated antibodies, then avidin-horseradish peroxidase, followed by $O$-phenylenediamine dihydrochloride (OPD), read at $490 \mathrm{~nm}$. Standard curves were used to calculate sample concentrations.

RSV-specific antibody ELISA. RSV-specific IgA, IgE, IgG1, and IgG2a was detected by coating 96-well plates with RSV antigen or Hep2 control materials, incubating overnight at $4{ }^{\circ} \mathrm{C}$ with different serum dilutions (1:2 dilutions starting at 1:100), and detecting Ig with biotinconjugated anti-mouse Ig antibodies (Becton Dickinson, Oxford, UK), avidin-horseradish peroxidase, and OPD as described above. Results were expressed as optical density values.

MACS sorting and adoptive transfer of splenic CD4 T cells. Mice were immunized, challenged, and depleted of IL-21 (or not) as described above. The mice were left for $28 \mathrm{~d}$, and the spleens were harvested. CD4 $\mathrm{T}$ cells were purified using a positive isolation kit (Miltenyi Biotech; according to the manufacturer's instructions). CD4 T-cell purity of $>90 \%$ was obtained. $5 \times 10^{6}$ cells were transferred IP into each recipient mouse $24 \mathrm{~h}$ before RSV challenge. Mice were monitored daily and BAL and lungs harvested $7 \mathrm{~d}$ PC.

Data analysis. A Student's $t$-test was used to analyze differences between the two groups. One-way analysis of variance (ANOVA) was used to analyze differences between more than two groups and significance was assumed at $P<0.05$. A Tukey's post test was used to identify differences between specific groups, with a significance threshold of $P<0.05$.

SUPPLEMENTARY MATERIAL is linked to the online version of the paper at http://www.nature.com/mi

\section{ACKNOWLEDGEMENTS}

This work was supported by the Center of Respiratory Infection (CRI; sponsor ref 083567/Z/07/Z), and the Wellcome Trust (Program sponsor refs 071381/Z/03/Z and 087805/Z/08/Z). We thank Sarah Wythe and Cecilia Johansson for their critical reading of this manuscript.

\section{DISCLOSURE}

The authors declared no conflict of interest.

c) 2013 Society for Mucosal Immunology

\section{REFERENCES}

1. Hall, C.B. et al. The burden of respiratory syncytial virus infection in young children. N. Engl. J. Med. 360, 588-598 (2009).

2. Falsey, A.R. Respiratory syncytial virus infection in adults. Semin. Respir. Crit. Care Med. 28, 171-181 (2007).

3. Openshaw, P.J. \& Tregoning, J.S. Immune responses and disease enhancement during respiratory syncytial virus infection. Clin. Microbiol. Rev. 18, 541-555 (2005).

4. Moghaddam, A. et al. A potential molecular mechanism for hypersensitivity caused by formalin-inactivated vaccines. Nat. Med. 12, 905-907 (2006).

5. Delgado, M.F. et al. Lack of antibody affinity maturation due to poor Toll-like receptor stimulation leads to enhanced respiratory syncytial virus disease. Nat. Med. 15, 34-41 (2009).

6. Lukacs, N.W., Smit, J.J., Mukherjee, S., Morris, S.B., Nunez, G. \& Lindell, D.M. Respiratory virus-induced TLR7 activation controls IL-17-associated increased mucus via IL-23 regulation. J. Immunol. 185, 2231-2239 (2010).

7. Mukherjee, S. et al. IL-17-induced pulmonary pathogenesis during respiratory viral infection and exacerbation of allergic disease. Am. J. Pathol. 179, 248-258 (2011).

8. Parrish-Novak, J. et al. Interleukin 21 and its receptor are involved in NK cell expansion and regulation of lymphocyte function. Nature 408, 57-63 (2000).

9. Coquet, J.M. et al. IL-21 is produced by NKT cells and modulates NKT cell activation and cytokine production. J. Immunol. 178, 2827-2834 (2007).

10. Chtanova, T. et al. T follicular helper cells express a distinctive transcriptional profile, reflecting their role as non-Th1/Th2 effector cells that provide help for B cells. J. Immunol. 173, 68-78 (2004).

11. Wei, L., Laurence, A., Elias, K.M. \& O'Shea, J.J IL-21 is produced by Th17 cells and drives IL-17 production in a STAT3-dependent manner. J. Biol. Chem. 282, 34605-34610 (2007).

12. Spolski, R. \& Leonard, W.J Interleukin-21: basic biology and implications for cancer and autoimmunity. Annu. Rev. Immunol. 26, 57-79 (2008).

13. Monteleone, G. et al. Control of matrix metalloproteinase production in human intestinal fibroblasts by interleukin 21. Gut 55, 1774-1780 (2006).

14. Suto, A. et al. Interleukin 21 prevents antigen-induced lgE production by inhibiting germ line C(epsilon) transcription of IL-4-stimulated B cells. Blood 100, 4565-4573 (2002).

15. Kasaian, M.T. et al. IL-21 limits NK cell responses and promotes antigenspecific Tcell activation: a mediator of the transition from innate to adaptive immunity. Immunity 16, 559-569 (2002).

16. Fantini, M.C. et al. IL-21 regulates experimental colitis by modulating the balance between Treg and Th17 cells. Eur. J. Immunol. 37, 3155-3163 (2007).

17. Peluso, I. et al. IL-21 counteracts the regulatory T cell-mediated suppression of human CD4 + T lymphocytes. J. Immunol. 178, 732-739 (2007).

18. Caruso, R. et al. A functional role for interleukin-21 in promoting the synthesis of the T-cell chemoattractant, MIP-3alpha, by gut epithelial cells. Gastroenterology 132, 166-175 (2007). 
19. Wurster, A.L. et al. Interleukin 21 is a T helper (Th) cell 2 cytokine that specifically inhibits the differentiation of naive Th cells into interferon gamma-producing Th1 cells. J. Exp. Med. 196, 969-977 (2002).

20. Strengell, M., Sareneva, T., Foster, D., Julkunen, I. \& Matikainen, S. IL-21 up-regulates the expression of genes associated with innate immunity and Th1 response. J. Immunol. 169, 3600-3605 (2002).

21. Nurieva, R. et al. Essential autocrine regulation by IL-21 in the generation of inflammatory T cells. Nature 448, 480-483 (2007).

22. Korn, T. et al. IL-21 initiates an alternative pathway to induce proinflammatory $\mathrm{T}(\mathrm{H}) 17$ cells. Nature 448, 484-487 (2007).

23. Tamagawa-Mineoka, R., Kishida, T., Mazda, O. \& Katoh, N. IL-21 reduces immediate hypersensitivity reactions in mouse skin by suppressing mast cell activation or IgE production. J. Invest. Dermatol. 131, 1513-1520 (2011).

24. Sondergaard, $H$. et al. Endogenous IL-21 restricts $C D 8+T$ cell expansion and is not required for tumor immunity. J. Immunol. 183, 7326-7336 (2009).

25. Ansari, N.A. et al. IL-27 and IL-21 are associated with $T$ cell $\mathbb{L}-10$ responses in human visceral leishmaniasis. J. Immunol. 186, 3977-3985 (2011).

26. Liu, Y. et al. Interleukin-21 maintains the expression of CD16 on monocytes via the production of IL-10 by human naive CD4 + T cells. Cell Immunol. 267, 102-108 (2011).

27. Pot, C. et al. Cutting edge: IL-27 induces the transcription factor c-Maf, cytokine IL-21, and the costimulatory receptor ICOS that coordinately act together to promote differentiation of $\mathrm{IL}-10$-producing $\operatorname{Tr} 1$ cells. $\mathrm{J}$. Immunol. 183, 797-801 (2009).

28. Brady, J. et al. The interactions of multiple cytokines control NK cell maturation. J. Immunol. 185, 6679-6688 (2010).

29. Publicover, J. et al. IL-21 is pivotal in determining age-dependent effectiveness of immune responses in a mouse model of human hepatitis B. J. Clin. Invest 121, 1154-1162 (2011).

30. Ertelt, J.M., Johanns, T.M., Rowe, J.H. \& Way, S.S. Interleukin (IL)-21independent pathogen-specific CD8 + T-cell expansion, and IL-21dependent suppression of CD4 + T-cell IL-17 production. Immunology 131, 183-191 (2010).

31. Chevalier, M.F. et al. HIV-1-specific interleukin-21+CD4+ T cell responses contribute to durable viral control through the modulation of HIV-specific CD8 + T cell function. J. Virol. 85, 733-741 (2011).

32. Yue, F.Y. et al. HIV-specific IL-21 producing CD4 + T cells are induced in acute and chronic progressive HIV infection and are associated with relative viral control. J. Immunol. 185, 498-506 (2010).

33. Rasmussen, T.K. et al. Increased interleukin 21 (IL-21) and IL-23 are associated with increased disease activity and with radiographic status in patients with early rheumatoid arthritis. J. Rheumatol. 37, 2014-2020 (2010).
34. Sarra, M. et al. Interferon-gamma-expressing cells are a major source of interleukin-21 in inflammatory bowel diseases. Inflamm. Bowel Dis. 16, 1332-1339 (2010).

35. Alwan, W.H., Kozlowska, W.J. \& Openshaw, P.J. Distinct types of lung disease caused by functional subsets of antiviral Tcells. J. Exp. Med. 179, 81-89 (1994)

36. Brandt, K., Bulfone-Paus, S., Foster, D.C. \& Ruckert, R. Interleukin-21 inhibits dendritic cell activation and maturation. Blood 102, 4090-4098 (2003).

37. Zhu, J. et al. Plasma cells and IL-4 in chronic bronchitis and chronic obstructive pulmonary disease. Am. J. Respir. Crit. Care Med. 175, 1125-1133 (2007).

38. Hussell, T., Khan, U. \& Openshaw, P. IL-12 treatment attenuates T helper cell type 2 and $B$ cell responses but does not improve vaccine-enhanced lung illness. J. Immunol. 159, 328-334 (1997).

39. Sun, J. et al. Autocrine regulation of pulmonary inflammation by effector T-cell derived IL-10 during infection with respiratory syncytial virus. PLOS Pathog. 7, e1002173 (2011).

40. Ozaki, K. et al. A critical role for IL-21 in regulating immunoglobulin production. Science 298, 1630-1634 (2002).

41. Vogelzang, A., McGuire, H.M., Yu, D., Sprent, J., Mackay, C.R. \& King, C. A fundamental role for interleukin-21 in the generation of T follicular helper cells. Immunity 29, 127-137 (2008).

42. Kuchen, S. et al. Essential role of IL-21 in B cell activation, expansion, and plasma cell generation during CD4 $+\mathrm{T}$ cell-B cell collaboration. J. Immunol. 179, 5886-5896 (2007).

43. Bryant, V.L. et al. Cytokine-mediated regulation of human B cell differentiation into Ig-secreting cells: predominant role of $\mathrm{IL}-21$ produced by CXCR5 + T follicular helper cells. J. Immunol. 179, 8180-8190 (2007).

44. Odegard, J.M. et al. ICOS-dependent extrafollicular helper Tcells elicit IgG production via IL-21 in systemic autoimmunity. J. Exp. Med. 205, 2873-2886 (2008).

45. Linterman, M.A. et al. IL-21 acts directly on B cells to regulate Bcl-6 expression and germinal center responses. J. Exp. Med. 207, 353-363 (2010).

46. Zotos, D. et al. IL-21 regulates germinal center B cell differentiation and proliferation through a B cell-intrinsic mechanism. J. Exp. Med. 207, 365-378 (2010).

47. Spolski, R. et al. IL-21 Promotes the pathologic immune response to pneumovirus infection. J. Immunol. 188, 1924-1932 (2012).

This work is licensed under the Creative Commons Attribution-NonCommercial-No Derivative Works 3.0 Unported License. To view a copy of this license, visit http:// creativecommons.org/licenses/by-nc-nd/3.0/ 